Check for updates

Cite this: RSC Adv., 2018, 8, 18364

\title{
Synthesis of $\mathrm{MoS}_{2}$ nanosheets for mercury speciation analysis by HPLC-UV-HG-AFS
}

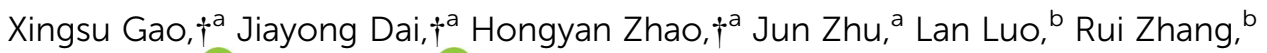 \\ Zhan Zhang (iD) *a and Lei Li (D)*a
}

Mercury species have aroused wide concern in the past several decades due to their high toxicity. However, it is still difficult to detect ultra-trace mercury species due to their biochemical transformation in complex samples. To establish a simpler and more sensitive method for pre-concentration and determination of trace mercury species, molybdenum disulfide $\left(\mathrm{MoS}_{2}\right)$ nanosheets with sulfur-rich characteristics and enlarged interlayer spacing were prepared by a hydrothermal method coupled with a sonication-assisted liquid exfoliation method and acted as solid-phase extraction adsorbent. The nano-MoS 2 had high adsorption capacity, fast adsorption rate and excellent selectivity towards mercury ions $\left(\mathrm{Hg}^{2+}\right)$, methyl mercury $\left(\mathrm{MeHg}^{+}\right)$and ethyl mercury $\left(\mathrm{EtHg}^{+}\right)$in a wide $\mathrm{pH}$ range and complex matrices. And it could be easily regenerated by $4 \mathrm{~mol} \mathrm{L^{-1 }} \mathrm{HCl}$ and reused several times. After optimizing HPLC-UV-HG-AFS conditions, a great linearity (1.0-10.0 $\mu \mathrm{g} \mathrm{L}^{-1}, R^{2}=0.999$ for $\mathrm{Hg}^{2+}, \mathrm{MeHg}^{+}$and $\mathrm{EtHg}^{+}$), lower detection limits $\left(0.017,0.037\right.$ and $0.021 \mathrm{ng} \mathrm{mL}^{-1}$ for $\mathrm{Hg}^{2+}, \mathrm{MeHg}^{+}$and $\mathrm{EtHg}^{+}$, respectively), relative standard deviations $(<5 \%)$ and addition recoveries of the samples within $82.75-113.38 \%$ were observed. In summary, trace inorganic and organic mercury species in environmental and biological samples could be selectively enriched by the prepared nano-MoS 2 and efficiently seperated and detected by HPLC-UVHG-AFS. The present study will help provide a better strategy for environmental monitoring and health assessment of mercury pollutants.

Received 4th March 2018 Accepted 11th May 2018

DOI: 10.1039/c8ra01891j

rsc.li/rsc-advances

\section{Introduction}

Mercury compounds are dangerous pollutants due to their bioaccumulation and persistence in the environment and ecosystems. ${ }^{1}$ Different mercury species have dissimilar toxicity, and different transport pathways and biogeochemical behaviours. Inorganic mercury can be transformed into more toxic organic mercury, which is easier to accumulate in the human body by the respiratory and gastrointestinal tract, and then damage the central nervous system. ${ }^{2}$ Therefore, it is urgent to develop sensitive methods for speciation analysis of mercury in environmental and biological samples to determine their different risks to public health.

During the past few decades, atomic adsorption spectrometry (AAS), ${ }^{3}$ atomic emission spectrometry (AES), ${ }^{4}$ atomic fluorescence spectrometry (AFS) ${ }^{5}$ and inductively coupled plasma mass spectrometry (ICP-MS) ${ }^{6}$ are usually used to detect total mercury species but not a particular form. To distinguish

${ }^{a}$ Department of Hygiene Analysis and Detection, School of Public Health, Nanjing Medical University, 101 Longmian Avenue, Nanjing 211166, Jiangsu, P. R. China. E-mail:drleili@hotmail.com; zhanzhang@njmu.edu.cn; Fax: +86-25-8686-8499; Tel: +86-25-8686-8404; +86-25-8686-8402

${ }^{b}$ Nanjing Entry-exit Inspection and Quarantine Bureau, 110 Jiangjun Avenue, Nanjing 211106, Jiangsu, P. R. China

$\dagger$ These authors contributed equally to this work. different mercury species, hyphenated methods were developed. High performance liquid chromatography (HPLC)-AFS was one of the most widely used methods due to its simple operation, high sensitivity, strong anti-interference ability and wide accessibility to instruments. ${ }^{7}$ However, the concentrations of organic mercury in environmental and biological samples are too low to reach the detection limits of the HPLC-AFS system. Thus, pre-concentration plays a vital role in analysis of ultratrace mercury species.

Previous studies have shown that solid phase extraction (SPE) had higher selectivity and good reproducibility compared with liquid-liquid extraction. ${ }^{8}$ Various materials ${ }^{9,10}$ have been used as adsorbents for mercury species, Cd(II), $\mathrm{Zn}(\mathrm{II}), \mathrm{Ni}(\mathrm{II})$ and many other metal species, including thiolfunctionalized mesoporous silica (FMMS), ${ }^{11,12}$ thiolfunctionalized graphene oxide/Fe-Mn composite (SGO/Fe$\mathrm{Mn}){ }^{13}$ two-dimensional transition-metal dichalcogenides (TMDs), ${ }^{14,15}$ ion-imprinted magnetic nanoparticles (IIMN) ${ }^{16}$ and graphene/biochar composite (G/BC).${ }^{17}$ As a typical TMD, molybdenum disulfide $\left(\mathrm{MoS}_{2}\right)$ has been used in the preconditioning of environmental samples due its few-layered structure, high special surface area, abundant binding sites (sulfur atoms) and strong affinity towards $\mathrm{Hg}^{0}$ and $\mathrm{Hg}^{2+} \cdot{ }^{18,19}$ However, nano- $\mathrm{MoS}_{2}$ for simultaneously enriching inorganic and organic mercury species in environmental and biological 
samples has not been reported. In the present study, a hydrothermal method in combination with sonication-assisted liquid exfoliation was used to obtain nano-MoS $\mathrm{M}_{2}$ with fewerlayers, expanded inter-layer distance and abundant active sites. High adsorption and desorption efficiency were also achieved by adjusting physicochemical parameters. Finally, a method of HPLC-UV irradiation (UV)-hydride generation (HG)-AFS was developed for detecting trace mercury species in real samples.

\section{Experimental}

\subsection{Reagents and materials}

Thiourea and sodium molybdate dehydrate $\left(\mathrm{Na}_{2} \mathrm{MoO}_{4} \cdot 2 \mathrm{H}_{2} \mathrm{O}\right.$, 99.0\%), acetic ammonium $\left(\mathrm{CH}_{3} \mathrm{COONH}_{4}, 98.0 \%\right)$, potassium hydroxide ( $\mathrm{KOH}, 85.0 \%)$, sodium hydroxide ( $\mathrm{NaOH}, 98.0 \%)$, potassium persulfate $\left(\mathrm{K}_{2} \mathrm{~S}_{2} \mathrm{O}_{8}, 99.0 \%\right)$, hydrochloric acid $(\mathrm{HCl}$, $36-38 \%)$ and sodium borohydride $\left(\mathrm{NaBH}_{4}, 97.0 \%\right)$ were purchased from Sinopharm Chemical Reagent Co., Ltd. (Beijing, China) and they were analytical reagent grade. L-cysteine (98.5\%) and methanol (chroma-pure, 99.9\%) were obtained from Sigma-Aldrich reagents Co., Ltd. (MO, USA). The standard solution of mercury ion $\left(\mathrm{Hg}^{2+}\right.$, GBW08617), methylmercury $\left(\mathrm{MeHg}^{+}, \mathrm{GBW}\right.$ 8675) and ethyl mercury $\left(\mathrm{EtHg}^{+}, \mathrm{GBW}(\mathrm{E})\right.$ 081524) were purchased from the National Research Center for certified reference materials (Beijing, China). All reagents used in the experiments were prepared by ultrapure water $(18.2 \mathrm{M} \Omega \mathrm{cm})$.

\subsection{Apparatus and HPLC-UV-HG-AFS analysis procedure}

Different mercury species were measured by HPLC-AFS (SA-20 and AFS-922, Beijing JiTian Apparatus Co., Ltd, China). The HPLC system was equipped with quaternary pump, degasser, manual stainless sampler injector and $100 \mu \mathrm{L}$ sample loop. Ultrasonic apparatus (KH-500DB, China) was used for nano$\mathrm{MoS}_{2}$ synthesis; field emission scanning electron microscope (FESEM, Zeiss merlin, Germany), JEM-2100 High resolution transmission electron microscopy (HRTEM, JEOL, Japan), atomic force microscopy (AFM, NT-MDT Prima, RUS), X-ray diffraction (XRD, Bruker AXS, DEU), X-ray photoelectron spectroscopy ESCALAB 250Xi Instrument (XPS, Thermo, USA) and Raman HORIBA evolution microscopy (HORIBA, FRA) were employed to make $\mathrm{MoS}_{2}$ characterization.
Procedure of HPLC-UV-HG-AFS: Step 1: separation, mercury species (inorganic and organic mercury) were separated through an Athena C18 column $(250 \times 4.6 \mathrm{~mm}, 5 \mu \mathrm{m}, \mathrm{CNW}$, Germany), an isocratic elution profile was used for chromatographic separation of mercury species. Step 2: oxidization, all mercury species were converted to inorganic mercury after oxidization and the irradiation of UV lamp (150 W). Step 3: detection, elemental mercury vapour was purged into the gasliquid separator and dragged into the detector by argon stream and the detection limits were $0.165,0.190,0.192 \mu \mathrm{g} \mathrm{L}^{-1}$ for $\mathrm{Hg}^{2+}, \mathrm{MeHg}^{+}$and $\mathrm{EtHg}^{+}$, respectively. Other instrument conditions can be seen in Table 1.

\subsection{Preparation and characterization of nano- $\mathrm{MoS}_{2}$}

2.3.1 Preparation of adsorbent. After comparing the simplicity and effectiveness of hydrothermal, ${ }^{20,21}$ chemical vapour deposition, ${ }^{22-24}$ ion-intercalated exfoliation ${ }^{25,26}$ and sonication or microwave-assisted exfoliation methods, ${ }^{27,28}$ hydrothermal method in combination with sonication-assisted liquid exfoliation method was used to synthesize $\mathrm{MoS}_{2}$ with expanded interlayer spacing. $4.959 \mathrm{~g}$ thiourea and $3.678 \mathrm{~g}$ $\mathrm{Na}_{2} \mathrm{MoO}_{4} \cdot 2 \mathrm{H}_{2} \mathrm{O}$ were dissolved into $75 \mathrm{~mL}$ ultrapure water and heated at $180{ }^{\circ} \mathrm{C}$ for $24 \mathrm{~h}$. After cooling to room temperature, the obtained products were placed under sonication at $150 \mathrm{~W}$ for $12 \mathrm{~h}$. Finally, the materials were washed with ultrapure water for several times and heated at $60{ }^{\circ} \mathrm{C}$ overnight.

2.3.2 Adsorption and desorption. $100 \mu \mathrm{g} \mathrm{MoS}_{2}$ was added into $5 \mathrm{~mL}$ ultrapure water containing $200 \mu \mathrm{g}$ mercury species after the $\mathrm{pH}$ was adjusted to $5.0 \pm 0.1$ by $0.1 \mathrm{~mol} \mathrm{~L}^{-1} \mathrm{NaOH}$ and $\mathrm{HNO}_{3}$. Adsorption was conducted by shaking at $500 \mathrm{rpm}$ and 25 $\pm 1{ }^{\circ} \mathrm{C}$ for $10 \mathrm{~min}$. After reaching to equilibrium, $\mathrm{MoS}_{2}$ was separated by centrifugation and the supernatant was used to measure mercury species by HPLC-UV-HG-AFS. In terms of desorption process, $5 \mathrm{~mL} \mathrm{HCl} \mathrm{solution} \mathrm{as} \mathrm{eluent} \mathrm{was} \mathrm{added} \mathrm{into}$ the precipitation and then vortexed at $1000 \mathrm{rpm}$ and $25 \pm 1{ }^{\circ} \mathrm{C}$ for $10 \mathrm{~min}$. Then the eluent was obtained by centrifugation for subsequent HPLC-UV-HG-AFS analysis. The blank test was also conducted in the same process.

The adsorption kinetic and isotherm researches were designed according to previous study. ${ }^{29}$ In the adsorption kinetic experiments, $1.0 \mathrm{mg}$ nano- $\mathrm{MoS}_{2}$ was added into $5 \mathrm{~mL}$ $200 \mathrm{mg} \mathrm{L}^{-1} \mathrm{Hg}^{2+}, 2 \mathrm{mg} \mathrm{L}^{-1} \mathrm{MeHg}^{+}$and $2 \mathrm{mg} \mathrm{L}^{-1} \mathrm{EtHg}^{+}$solution with $\mathrm{pH}$ values of $5.0 \pm 0.1$ and adsorbed for different time

Table 1 Experimental conditions of HPLC-HG-UV-AFS

Instrument conditions

Column and sample injection volume

Mobile phase composition and flow rate

Photomultiplier tube negative high pressure

High performance hollow cathode lamp current

Atomic heater height

Carrier and shielded argon flow

Carrying current

Reducing agent

Oxidizing agent
Parameters

Athena-C18 column $(250 \times 4.6 \mathrm{~mm}, 5 \mu \mathrm{m}), 100 \mu \mathrm{L}$

$\mathrm{CH}_{3} \mathrm{OH} 10 \% / 90 \% \mathrm{H}_{2} \mathrm{O}-0.46 \% \mathrm{NH}_{4} \mathrm{Ac}-0.12 \% \mathrm{~L}$-cys, $1.0 \mathrm{~mL} \mathrm{~min}^{-1}$

$270 \mathrm{~V}$

$30 \mathrm{~mA}$

$8 \mathrm{~mm}$

300 and $600 \mathrm{~mL} \mathrm{~min}^{-1}$

$2 \% \mathrm{HNO}_{3}(\mathrm{v} / \mathrm{v})$

$2 \% \mathrm{NaBH}_{4}(\mathrm{~m} / \mathrm{v})-0.5 \% \mathrm{NaOH}(\mathrm{m} / \mathrm{v})$

$0.5 \% \mathrm{~K}_{2} \mathrm{~S}_{2} \mathrm{O}_{4}(\mathrm{~m} / \mathrm{v})-0.25 \% \mathrm{KOH}(\mathrm{m} / \mathrm{v})$ 
intervals $(0,1,5,10,20,30,40,50,60 \mathrm{~min})$. Then, $\mathrm{MoS}_{2}$ was separated and the concentrations of mercury species in supernatant liquid were measured. In the adsorption isotherm experiments, $1.0 \mathrm{mg} \mathrm{MoS}$ was added into $5 \mathrm{~mL} \mathrm{Hg}^{2+}$ and alkyl mercury aqueous solution $(0,50,100,200,250,300,350$, $400 \mathrm{mg} \mathrm{L}^{-1}$ for $\mathrm{Hg}^{2+}$ and 0, 10, 20, 30, 40, $50 \mathrm{mg} \mathrm{L}^{-1}$ for $\mathrm{MeHg}^{+}$, $\mathrm{MeHg}^{+}$was selected to represent alkyl mercury in this experiment). Higher concentration of $\mathrm{Hg}^{2+}$ should be avoided to form $\mathrm{Hg}(\mathrm{OH})_{2}$, which may result in overestimating the adsorption capacity of $\mathrm{MoS}_{2}$. After enough adsorption time, the concentrations of mercury species in supernatant liquid were also measured.

2.3.3 Effects of $\mathbf{p H}$ and co-existing metal ions. $1.0 \mathrm{mg} \mathrm{MoS}_{2}$ was added into $10 \mathrm{~mL} 100 \mathrm{mg} \mathrm{L}{ }^{-1} \mathrm{Hg}^{2+}, 1 \mathrm{mg} \mathrm{L}^{-1} \mathrm{MeHg}^{+}$and $1 \mathrm{mg} \mathrm{L}{ }^{-1} \mathrm{EtHg}^{+}$solution and adsorbed for $10 \mathrm{~min}$ at the $\mathrm{pH}$ values ranged from 3.0 to 10.0 . Some several metal ions, which usually present together with inorganic and organic mercury species in environmental and biological samples, were selected to add into the mercury species solutions, including alkali metal ions and heavy metal ions $\left(0-20 \mathrm{mg} \mathrm{L}{ }^{-1} \mathrm{~K}^{+}, \mathrm{Na}^{+}, \mathrm{Ca}^{2+}\right.$, $\left.\mathrm{Mg}^{2+}, \mathrm{Cu}^{2+}, \mathrm{Fe}^{3+}, \mathrm{Pb}^{2+}, \mathrm{Ag}^{+}, \mathrm{Cd}^{2+}, \mathrm{As}^{3+}\right)$. After saturated adsorption time, the concentrations of mercury species in the supernatant liquid were measured.

\subsection{HPLC-UV-HG-AFS analysis and quality control}

Tap water, Tianyuan Lake water and fish tissue were collected from local laboratory and market (Nanjing, China) as real samples. The water samples were collected with glass containers, which were soaked with $10 \%$ nitric acid for $24 \mathrm{~h}$ and washed with ultrapure water for several times before sampling.
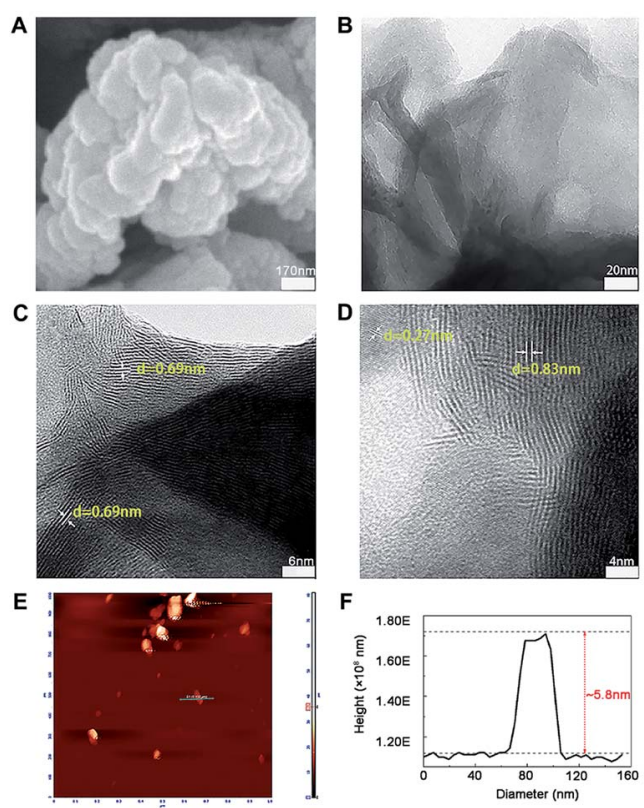

Fig. 1 Representative images of nano-MoS from (A) scanning electron microscope, (B) transmission electron microscope, (C and D) different versions of high resolution transmission electron microscope and (E) atomic force microscope. (F) The thickness of nano-MoS 2 was obtained from atomic force microscope.
The sampler was immersed in a certain depth underwater to avoid pollutant on sediment and lake surface for the reason that mercury species are easily adsorbed on suspended solids. 5\% nitric acid and $0.5 \%$ potassium permanganate as stabilizer were added into water samples, and the solution was filtered through $0.45 \mu \mathrm{m}$ microporous membrane before test. Solid samples were washed with ultrapure water, cut and immersed in $5 \mathrm{~mol} \mathrm{~L}^{-1}$ hydrochloric acid for $24 \mathrm{~h}$ and then shaking at $500 \mathrm{rpm}$ for $1 \mathrm{~h}$, finally the extracting solution was filtered through $0.45 \mu \mathrm{m}$ membrane and $\mathrm{pH}$ was adjusted to $5.0 \pm 0.1$ by $\mathrm{NaOH}$. Subsequently, the mercury species in these samples were enriched by prepared nano- $\mathrm{MoS}_{2}$ and then injected into HPLC-UV-HG-AFS for separation and detection. The blank experiments were also performed at the same time.

According to IUPAC, the detection limit was defined to be $\mathrm{LOD}=3 \times \mathrm{SD} / K$, where $\mathrm{SD}$ is the standard deviation of signal values obtained by measuring blank sample for six times, $K$ is the slope of the standard curve. The relative standard deviations (RSDs) of this method for $\mathrm{Hg}^{2+}, \mathrm{MeHg}^{+}$and $\mathrm{EtHg}^{+}$were evaluated at concentration of $2 \mu \mathrm{g} \mathrm{L}^{-1}, 6 \mu \mathrm{g} \mathrm{L} \mathrm{L}^{-1}$ and $10 \mu \mathrm{g} \mathrm{L}^{-1}$, respectively. Low $\left(0.5 \mu \mathrm{g} \mathrm{L}^{-1}\right)$, medium $\left(1.0 \mu \mathrm{g} \mathrm{L}^{-1}\right)$ and high $\left(1.5 \mu \mathrm{g} \mathrm{L}^{-1}\right)$ mercury species standard solution were added into the samples to calculate their recoveries, which could be used to estimate the accuracy.

\section{Results and discussion}

\subsection{Characterization of $\mathrm{MoS}_{2}$ nanomaterials}

The morphology and microstructure of prepared $\mathrm{MoS}_{2}$ were achieved from the SEM, TEM and HRTEM images (Fig. 1A-D). The diameter of $\mathrm{MoS}_{2}$ ranged from hundreds of nano-meters to micro-meters (Fig. 1A and B). The HRTEM images clearly showed the S-Mo-S layer had a curved stripe-like feature and the distance between layers was 0.69-0.83 nm (Fig. 1C and D), which was in good agreement with the typical thickness of monolayer $\mathrm{MoS}_{2},{ }^{30}$ indicating these nano-MoS had expanded interlayer spacing. The cross section analysis along with the line was conducted based on the AFM image according to previous study. ${ }^{31}$ As shown in Fig. $1 \mathrm{E}, \mathrm{MoS}_{2}$ had thin thickness at around several nano-meters, the step height between the substrate and the nanosheets was around $5.8 \mathrm{~nm}$ (Fig. 1F), indicating the nano- $\mathrm{MoS}_{2}$ might contain eight-layers for the monolayer thickness was $0.69 \mathrm{~nm}$.

As shown in Raman spectra (Fig. 2A), there were two characteristic peaks at the wavenumber of 376.2 and $401 \mathrm{~cm}^{-1}$, which were consistent with the $\mathrm{E}^{1}{ }_{2 \mathrm{~g}}$ and $\mathrm{A}_{1 \mathrm{~g}}$ mode of typical $\mathrm{MoS}_{2}$ layered structure, where $\mathrm{E}_{2 \mathrm{~g}}^{1}$ mode represents in-plane motion and $\mathrm{A}_{1 \mathrm{~g}}$ mode represents out-of-plane motion. ${ }^{32}$ The distance between the $\mathrm{E}_{2 \mathrm{~g}}^{1}$ and $\mathrm{A}_{1 \mathrm{~g}}$ peaks could indicate the variation in thickness. The frequency of $\mathrm{A}_{1 \mathrm{~g}}$ modes had a bit red shift after sonication for $12 \mathrm{~h}$ (curve a and b in Fig. 2A), indicating the thickness of $\mathrm{MoS}_{2}$ decreased with liquid exfoliation but in-plane structure had no change. ${ }^{33}$

Towards the XRD pattern (Fig. 2B), there was a significant difference between prepared nanomaterials and commercial bulk 2H-MoS ${ }_{2}$ (JCPDS 77-1716) and 2H-MoS ${ }_{2}$ crystal (PDF 01087-2416), one peak appeared at low-angle region $\left(10^{\circ}\right)$ 
A
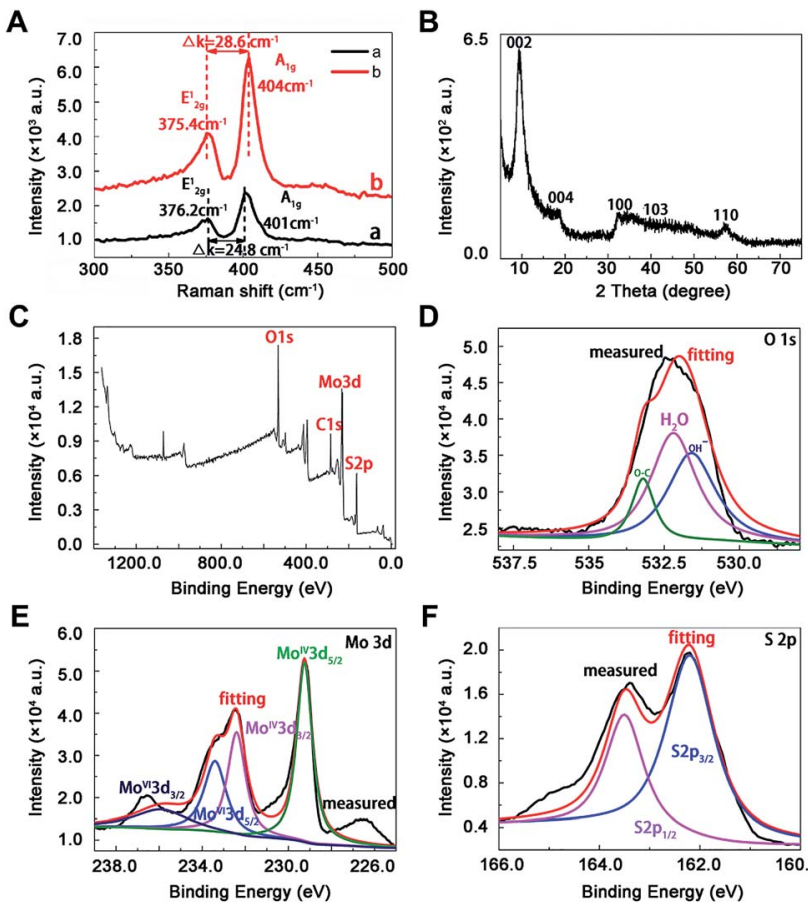

$\mathbf{F}$

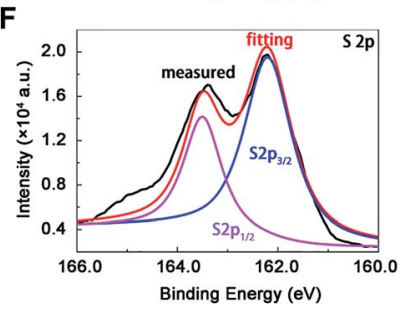

Fig. 2 Characterization of $\mathrm{MoS}_{2}$ by spectra. (A) Raman spectra of nano-MoS 2 with (curve a) and without (curve b) sonication, (B) X-ray diffraction pattern of nanO-MoS 2 X-ray photoelectron spectroscopy spectra of nano-MoS 2 in the (C) survey, (D) O 1s, (E) Mo 3d and (F) S 2p region.

corresponding to (002) reflection with $d$-spacing values of $8.3 \AA$, which could be ascribed to oxygen incorporation and indicated an enlarged interlayer spacing of $\mathrm{MoS}_{2}$. This result agreed well with above HRTEM image. The distance value was estimated to be near $5.13 \AA$ according to the interlayer spacing value (8.3 $\mathrm{A}$ ) and the thickness $(3.17 \AA)$ of the S-Mo-S structure, ${ }^{30}$ which was larger than the values of bulk $\mathrm{MoS}_{2}(2.98 \AA)$ and other nano$\mathrm{MoS}_{2}$ with lithium ion intercalated (3.18-3.73 $\left.\mathrm{A}\right),{ }^{21}$ thus the interlayer spacing of the prepared materials was enough to embed mercury ions. In this way, highly crystalline nano- $\mathrm{MoS}_{2}$ with expanded inter-layer spacing had been synthesized successfully.

The chemical states of $\mathrm{O}$, Mo and $\mathrm{S}$ atoms were obtained in XPS spectra (Fig. 2C-F). The $\mathrm{O}_{1 \mathrm{~s}}$ results might derive from the minor oxidation in the natural formation process (Fig. 2D), and the binding energies of Mo and $\mathrm{S}$ were in good agreement with those of commercial $\mathrm{MoS}_{2}$, where $232.5 \mathrm{eV}$ and $229.4 \mathrm{eV}$ belonged to $\mathrm{Mo}_{3 \mathrm{~d} 3 / 2}$ and $\mathrm{Mo}_{3 \mathrm{~d} 5 / 2}$ (Fig. 2E), $163.5 \mathrm{eV}$ and $162.2 \mathrm{eV}$ belonged to $\mathrm{S}_{2 \mathrm{p} 1 / 2}$ and $\mathrm{S}_{2 \mathrm{p} 3 / 2}$ in nano-MoS $\mathrm{S}_{2}$ (Fig. 2F). Meanwhile, some newly appeared peaks at $233.5 \mathrm{eV}$ and $236 \mathrm{eV}$ belonged to $\mathrm{Mo}_{3 \mathrm{~d} 5 / 2}$ and $\mathrm{Mo}_{3 \mathrm{~d} 3 / 2}$ in $\mathrm{MoS}_{3}$, probably due to partial surface oxidation upon exposure to air in the process of exfoliation. ${ }^{34}$

\subsection{Pre-concentration conditions of mercury species}

3.2.1 Experiment of pH. Nano- $\mathrm{MoS}_{2}$ exhibited high adsorption capacity to $\mathrm{Hg}^{2+}, \mathrm{MeHg}^{+}$and $\mathrm{EtHg}^{+}$in the whole $\mathrm{pH}$ range (Fig. 3A). The adsorption amount of $\mathrm{MoS}_{2}$ increased
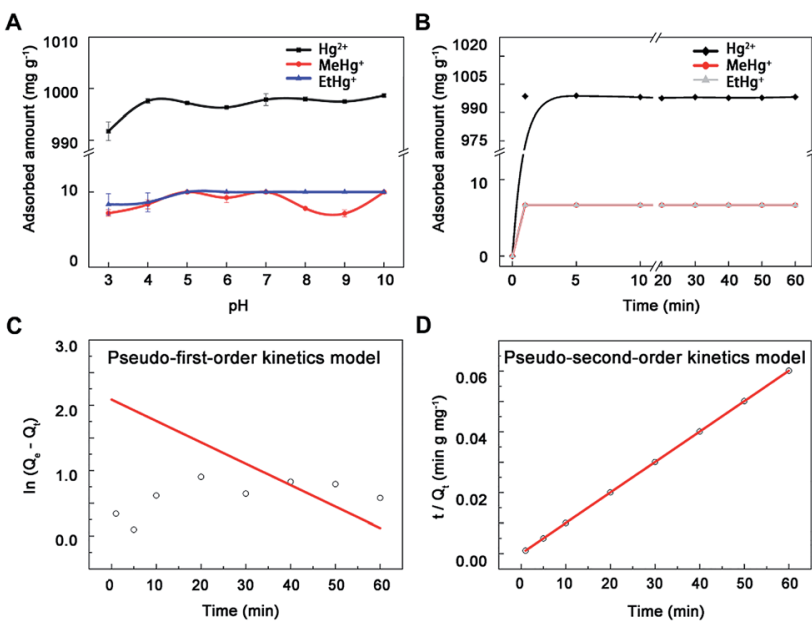

Fig. 3 The adsorption of mercury species onto nano-MoS 2 . (A) Effect of $\mathrm{pH}$ on mercury species adsorption onto nano-MoS 2 . (B) Adsorption kinetics spectra of $\mathrm{MoS}_{2}$ towards mercury species, (C) linear fitting results of pseudo-first-order kinetics model and (D) pseudo-secondorder kinetics model toward mercury ions.

slightly within 3.0-5.0 and then kept at a volatile balance with $\mathrm{pH}$ increasing to 7.0. Previous study had shown that the surface of $\mathrm{MoS}_{2}$ was negative and the zeta potential decreased along with the increases of $\mathrm{pH}$ values. ${ }^{29}$ Thus, these results could be ascribed to two hypotheses: one is electrostatic attraction between the negatively charged $\mathrm{MoS}_{2}$ and positively charged mercury species, another is competitive binding between hydrogen ions and mercury species to active sites on the surface of $\mathrm{MoS}_{2}$. The electrostatic interaction will increase along with the increasing of $\mathrm{pH}$ before 5.0. However, low $\mathrm{pH}$ values provided excess $\mathrm{H}^{+}$to compete with $\mathrm{Hg}^{2+}$ for active sites, leading to a lower adsorption capacity. In terms of higher $\mathrm{pH}$ values, mercury would be exist in the less positive form of $\mathrm{HgOH}^{+}(5.0-$ 7.0) and $\mathrm{Hg}(\mathrm{OH})_{2}(7.0-10.0),{ }^{35}$ resulting in the balance of adsorption in $\mathrm{pH}$ range of 5.0-10.0. Therefore, the $\mathrm{pH}$ value only needed a little adjustment to simplify the experimental process and avoid interference.

3.2.2 Adsorption kinetics experiment. The adsorption proceeded at a high rate during the first $2 \mathrm{~min}$ and reached equilibrium at around $5 \mathrm{~min}$, meanwhile the adsorption percentages were clearly $100 \%$ (Fig. 3B), which probably resulted from large surface area and short diffusion path of $\mathrm{MoS}_{2}{ }^{21,36}$ To further explore the mechanism of the adsorption process, pseudo-first-order (eqn (1)) and pseudo-second-order kinetics models (eqn (2)) were used (mercury ion as a model ion in this

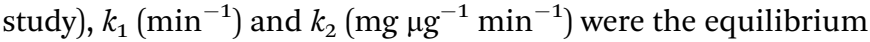
rate constants of pseudo-first-order and pseudo-second-order, $Q_{\mathrm{t}}\left(\mu \mathrm{g} \mathrm{mg}^{-1}\right)$ and $Q_{\mathrm{e}}\left(\mu \mathrm{g} \mathrm{mg}^{-1}\right)$ were the adsorbed concentration at time $\mathrm{t}(\mathrm{min})$ and equilibrium time. The adsorption kinetics data $\left(R^{2}=1\right)$ fitted better with the pseudo-second-order model than the other (Fig. 3C and D), suggesting the adsorbent had uniform surface and there was a chemical interaction between adsorbent and adsorbate. ${ }^{\mathbf{1 4}}$ Additionally, the calculated data (1000 $\mathrm{mg} \mathrm{g}^{-1}$ for $\mathrm{Hg}^{2+}$ ) from the pseudo-second-order curve were consistent with results in this study, indicating the 

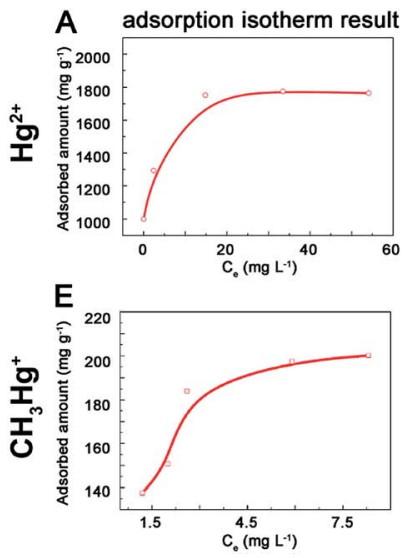
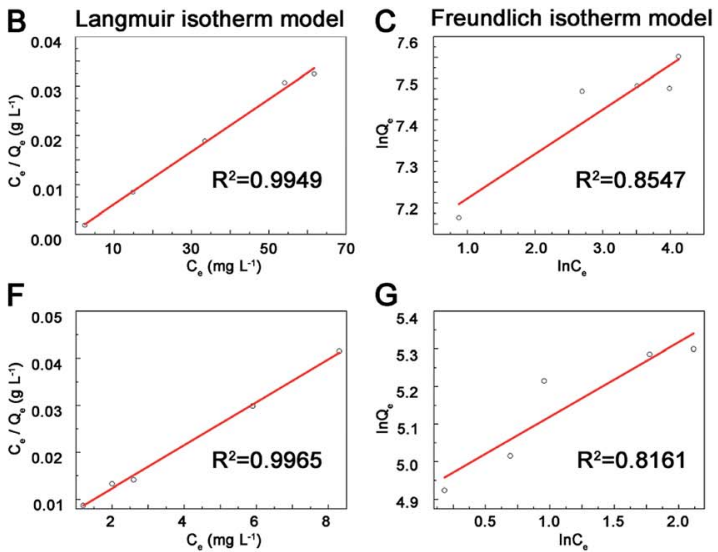
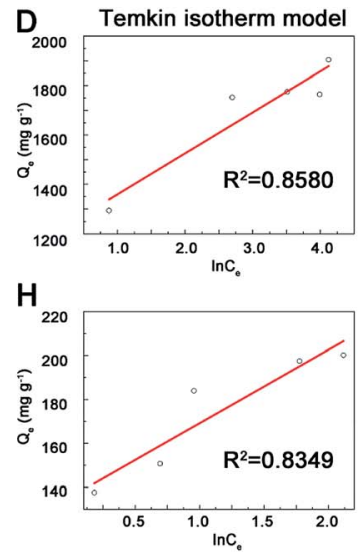

Fig. 4 Adsorption isotherm spectra of $M_{0}$ towards (A) mercury (E) and methylmercury ions, linear fitting results of Langmuir (B and F), Freundlich ( $C$ and $G)$, Temkin $(D$ and $H)$ towards mercury and methyl mercury ions.

adsorption processes were under chemical process control. Thus, 5 min was selected as adsorption time to ensure complete reaction.

$$
\begin{gathered}
\ln \left(Q_{\mathrm{e}}-Q_{\mathrm{t}}\right)=\ln Q_{\mathrm{e}}-K_{1} t \\
t / Q_{\mathrm{t}}=1 /\left(K_{2} Q_{\mathrm{e}}{ }^{2}\right)+t / Q_{\mathrm{e}}
\end{gathered}
$$

3.2.3 Adsorption isotherms experiment. The adsorption capacity increased along with the initial $\mathrm{Hg}^{2+}$ concentration and then reached to equilibrium (Fig. 4). The maximum adsorption capacities of prepared $\mathrm{MoS}_{2}$ were $1.77 \mathrm{~g} \mathrm{~g}^{-1}$ for $\mathrm{Hg}^{2+}$ (Fig. 4A) and $200 \mathrm{mg} \mathrm{g}^{-1}$ for $\mathrm{MeHg}^{+}$(Fig. 4E), which were higher than other adsorbents reported previously (Table 1) and these effects may result from the rich exposure of active sites on the surface of $\mathrm{MoS}_{2}$. To further explore the mechanism of adsorption process, the Langmuir (eqn (3)), Freundlich (eqn (4)) and Temkin (eqn (5)) isotherm models were used. $Q_{\mathrm{e}}\left(\mathrm{mg} \mathrm{g}^{-1}\right)$ was the adsorbed concentration at equilibrium time, $Q_{\mathrm{m}}\left(\mathrm{mg} \mathrm{g}^{-1}\right)$ was the maximum adsorption capacity of Langmuir model, $C_{\mathrm{e}}$ was the aqueous concentration of adsorption equilibrium, $K_{1}$, $K_{2}$ and $K_{3}$ represented the Langmuir constant $\left(\mathrm{L} \mathrm{mg}^{-1}\right)$, Freundlich constant $\left(\mathrm{mg} \mathrm{g}^{-1}\right)$ and Temkin constant $\left(\mathrm{L} \mathrm{g}^{-1}\right), n$ and $B$ represented the adsorption intensity constant and adsorption heat constant $\left(\mathrm{J} \mathrm{mol}^{-1}\right)$. The isotherms data fitted better with Langmuir model than the other two models for the correlation coefficient $\left(R^{2}=0.995,0.996\right.$ for $\mathrm{Hg}^{2+}$ and $\left.\mathrm{MeHg}^{+}\right)$ (Fig. 4B-D and F-H). Furthermore, the calculated data $\left(Q_{\mathrm{m}}\right)$ (1881.8 and $218.3 \mathrm{mg} \mathrm{g}^{-1}$ for $\mathrm{Hg}^{2+}$ and $\mathrm{MeHg}^{+}$) from the Langmuir curves were close to the results data, indicating the adsorption was monolayer. According to previous study, ${ }^{21} \mathrm{Hg}^{2+}$ could spontaneously intercalate into S-Mo-S layers and then interact with $\mathrm{S}$ atoms to form $\mathrm{Hg}$-S species. In terms of organic mercury species, previous study ${ }^{\mathbf{1 1}}$ suggested that $\mathrm{MeHg}^{+}$and $\mathrm{EtHg}^{+}$could react with sulfhydryl group, but the sulfhydryl groups had higher affinity to divalent $\mathrm{Hg}^{2+}$ rather than monovalent $\mathrm{MeHg}^{+}$when they were together. The interaction between $\mathrm{MeHg}^{+}$and $\mathrm{MoS}_{2}$ might ascribe to the electrostatic attraction and binding cooperation. The adsorption capacity of $\mathrm{MoS}_{2}$ towards $\mathrm{MeHg}^{+}$was less than $\mathrm{Hg}^{2+}$, probably because $\mathrm{MeHg}^{+}$ could only bind to active sites on the surface-layer of $\mathrm{MoS}_{2}$ but not intercalate into interlayers for space steric hindrance effects. Moreover, the actual adsorption capacities were lower than the theoretical values (the theoretical adsorption capacity is estimated to be $2587 \mathrm{mg} \mathrm{Hg}^{2+} \mathrm{g}^{-1} \mathrm{MoS}_{2}$ based on a stoichiometric $\mathrm{S} / \mathrm{Hg}$ ratio of $1: 1$ ) might due to the oxidation of exposed edge sites on $\mathrm{MoS}_{2}$ surface layers. ${ }^{34}$

$$
\begin{gathered}
\text { Langmuir: } C_{\mathrm{e}} / Q_{\mathrm{e}}=C_{\mathrm{e}} / Q_{\mathrm{m}}+1 /\left(K_{1} \times Q_{\mathrm{m}}\right) \\
\text { Freundlich: } \ln Q_{\mathrm{e}}=\left(\ln C_{\mathrm{e}}\right) / n+\ln K_{2} \\
\text { Temkin: } Q_{\mathrm{e}}=B \times \ln \left(K_{3} \times C_{\mathrm{e}}\right)
\end{gathered}
$$

3.2.4 Eluent concentration and elution time. Acid and Lcysteine were chosen as eluents due to effects of $\mathrm{pH}$ and mobile phase on elution efficiency. ${ }^{11} \mathrm{Hg}^{2+}$ was completely eluted by $\mathrm{HCl}, \mathrm{MeHg}^{+}$can quantitatively desorbed with $\mathrm{L}$-cys, while $\mathrm{EtHg}^{+}$ could not be eluted absolutely (Fig. 5A). Progressively, a series concentration of $\mathrm{HCl}$ was set out as eluent and these mercury species were almost entirely eluted by $4 \mathrm{~mol} \mathrm{~L}^{-1} \mathrm{HCl}$ (Fig. 5B). Except for eluent type and concentration, elution time may affect the elution efficiency either. The desorption proceeded at a high rate in the first $5 \mathrm{~min}$ and reached to equilibrium at around $10 \mathrm{~min}$, meanwhile the recoveries could reach to $90 \%$ (Fig. 5C). Therefore, $4 \mathrm{~mol} \mathrm{~L}^{-1} \mathrm{HCl}$ and 10 min elution time were selected for regeneration process and the adsorption capacity of $\mathrm{MoS}_{2}$ towards $\mathrm{Hg}^{2+}$ maintained relatively stable during three recycles of adsorption and regeneration (Fig. 5D).

3.2.5 Interference of co-existing metal ions. Previous studies showed that $\mathrm{MoS}_{2}$ had superior selectivity toward $\mathrm{Hg}^{2+}$ and negligible capture capability for various competitive ions, ${ }^{26}$ including alkali metal ions $\left(\mathrm{K}^{+}, \mathrm{Na}^{+}, \mathrm{Ca}^{2+}, \mathrm{Mg}^{2+}\right)$ and heavy metal ions $\left(\mathrm{Cu}^{2+}, \mathrm{Fe}^{3+}, \mathrm{Pb}^{2+}, \mathrm{Ag}^{+}, \mathrm{Cd}^{2+}, \mathrm{As}^{3+}\right)$. The adsorption efficiency of $\mathrm{MoS}_{2}$ toward $\mathrm{MeHg}^{+}$and $\mathrm{EtHg}^{+}$but not $\mathrm{Hg}^{2+}$ decreased significantly when the concentration of 
A
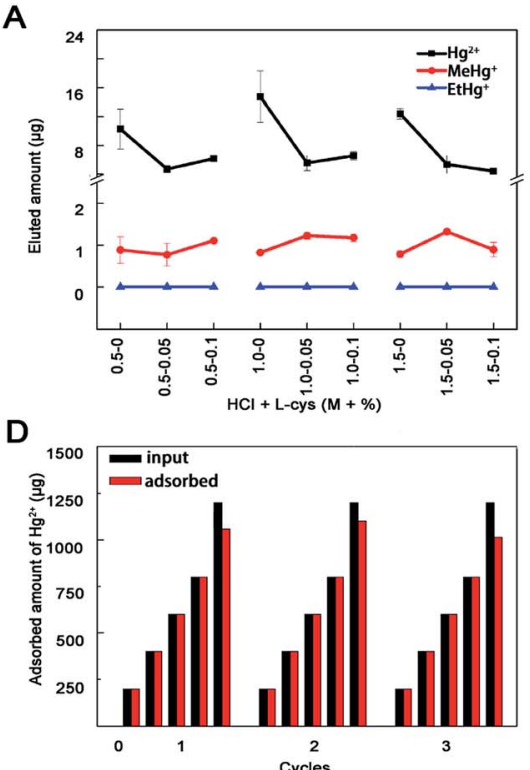

B

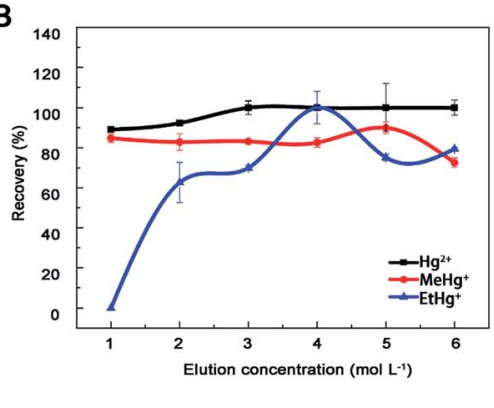

E

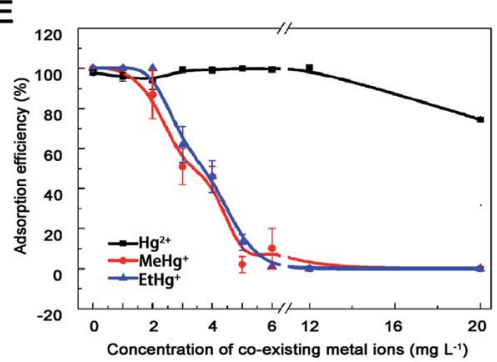

C

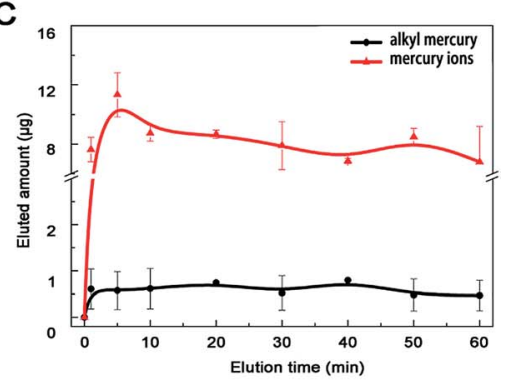

$\mathbf{F}$

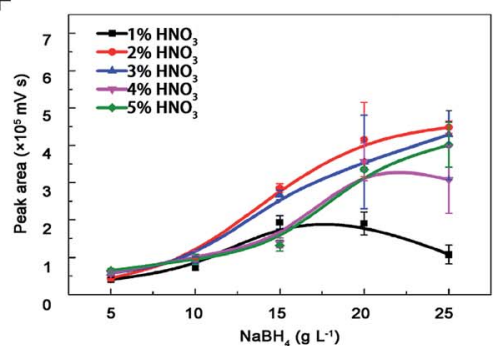

Fig. 5 Optimization of the experimental conditions. Effects of (A) $\mathrm{HCl}-\mathrm{L}-$ cys concentration, (B) $\mathrm{HCl}$ concentration and (C) elution time on mercury species desorption from nano-MoS . (D) Adsorption capacity of $\mathrm{MoS}_{2}$ during three cycles of regeneration and reuse. The material was regenerated by introducing $4 \mathrm{~mol} \mathrm{~L}^{-1} \mathrm{HCl}$. (E) Effect of alkali metal ions ( $\mathrm{K}, \mathrm{Na}, \mathrm{Ca}, \mathrm{Mg}$ ) and heavy metal ions $(\mathrm{Cu}, \mathrm{Fe}, \mathrm{Ag}, \mathrm{As}, \mathrm{Pb}, \mathrm{Cd})$ on $\mathrm{Hg}{ }^{2+}$ $\left(6.0 \mathrm{mg} \mathrm{L}^{-1}\right), \mathrm{MeHg}^{+}\left(0.2 \mathrm{mg} \mathrm{L}^{-1}\right)$ and EtHg $\left(0.2 \mathrm{mg} \mathrm{L}^{-1}\right)$ adsorption onto nano-MoS $\left(6 \mathrm{mg} \mathrm{L}^{-1}\right)$. (F) Effects of carrying current and reducing agent ratio on HPLC-AFS signal intensity. Nitric acid acted as carrying current and its' concentration ranged from 1-5\%, sodium borohydride acted as reducing agent and its' concentration ranged from 5-25 g L-1. Once one parameter changed, the others would be under their optimal conditions.

co-existing metal ions was within $2-12 \mathrm{mg} \mathrm{L}^{-1}$ (Fig. 5E), which may result from their similar affinity to the active sites (sulfur atoms), bigger steric hindrance and weaker electrostatic interactions between monovalent alkyl mercury and $\mathrm{MoS}_{2}$. Generally, the concentrations of co-existing heavy metal ions in environmental and biological samples were lower than our experiment settings, therefore this prepared material could be used for enriching mercury species in real samples.

Table 2 Applications of $\mathrm{MoS}_{2}$ nanoparticles as adsorbent for mercury species

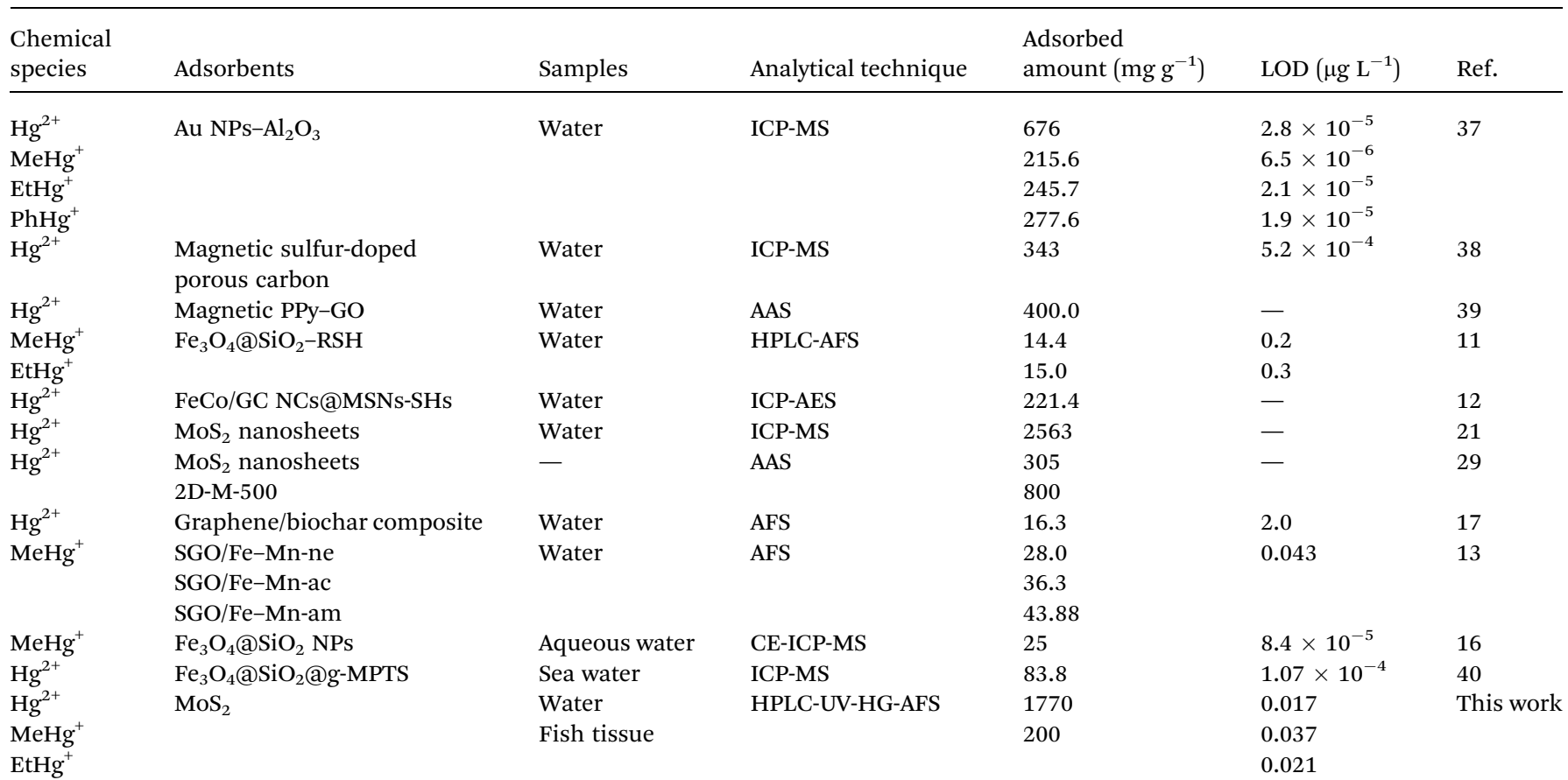


Table 3 Analysis of mercury species by HPLC-UV-HG-AFS after pre-concentrated by $\mathrm{MoS}_{2}$ adsorbent

\begin{tabular}{llll}
\hline Species & $\mathrm{Hg}^{2+}$ & $\mathrm{MeHg}^{+}$ & $\mathrm{EtHg}^{+}$ \\
\hline Linear regression & $I=6535.5 \times \mathrm{C}+326.7$ & $I=6675.5 \times \mathrm{C}-886.0$ & $I=6406.8 \times \mathrm{C}-305.2$ \\
$R^{2}$ & 0.999 & 0.999 & 0.999 \\
RSD (\%), $\left[6 \mathrm{ng} \mathrm{mL}^{-1}, n=6\right]$ & 3.9 & 2.5 & 3.8 \\
LOD $(\mathrm{ng} \mathrm{mL})$ & 0.017 & 0.037 & 0.021
\end{tabular}

Table 4 Determination of mercury species in real sample

\begin{tabular}{|c|c|c|c|c|c|c|c|c|c|}
\hline \multirow[b]{2}{*}{ Samples } & \multicolumn{3}{|l|}{$\mathrm{Hg}^{2+}$} & \multicolumn{3}{|l|}{$\mathrm{MeHg}^{+}$} & \multicolumn{3}{|l|}{$\mathrm{EtHg}^{+}$} \\
\hline & $\begin{array}{l}\text { Added } \\
\left(\mathrm{ng} \mathrm{mL}^{-1}\right)\end{array}$ & $\begin{array}{l}\text { Found } \\
\left(\mathrm{ng} \mathrm{mL}^{-1}\right)\end{array}$ & Recovery (\%) & $\begin{array}{l}\text { Added } \\
\left(\mathrm{ng} \mathrm{mL}^{-1}\right)\end{array}$ & $\begin{array}{l}\text { Found } \\
\left(\text { ng mL } L^{-1}\right)\end{array}$ & Recovery (\%) & $\begin{array}{l}\text { Added } \\
\left(\text { ng } \mathrm{mL}^{-1}\right)\end{array}$ & $\begin{array}{l}\text { Found } \\
\left(\text { ng mL } L^{-1}\right)\end{array}$ & Recovery (\%) \\
\hline \multirow[t]{3}{*}{ Fish tissue } & 0 & 0.4963 & 0 & 0 & 0.0542 & 0 & 0 & $\mathrm{ND}^{a}$ & 0 \\
\hline & 0.5 & 0.9971 & 99.86 & 0.5 & 0.4411 & 88.22 & 0.5 & 0.4482 & 89.64 \\
\hline & 1.0 & 1.3448 & 84.85 & 1.0 & 0.8500 & 85.00 & 1.0 & 0.8319 & 83.19 \\
\hline & 0.5 & 1.4928 & 101.04 & 0.5 & 0.4137 & 82.75 & 0.5 & 0.5654 & 113.08 \\
\hline & 1.0 & 1.9363 & 94.86 & 1.0 & 1.0211 & 102.11 & 1.0 & 0.9772 & 97.72 \\
\hline & 1.5 & 2.5037 & 101.07 & 1.5 & 1.7007 & 113.38 & 1.5 & 1.6442 & 109.61 \\
\hline \multirow[t]{3}{*}{ Lake water } & 0 & 1.0189 & 0 & 0 & ND & 0 & 0 & ND & 0 \\
\hline & 0.5 & 1.4532 & 86.86 & 0.5 & 0.4229 & 84.58 & 0.5 & 0.4181 & 83.62 \\
\hline & 1.0 & 1.8805 & 86.16 & 1.0 & 1.0526 & 105.26 & 1.0 & 0.8451 & 84.51 \\
\hline
\end{tabular}

\subsection{HPLC-UV-HG-AFS analysis}

In this study, mobile phase including $10 \%$ methyl alcohol, $0.12 \%$ L-cys and $0.46 \%$ acetic ammonium severed as organic modifier, chelating agent and buffer to optimize and separate the chromatographic peaks of different mercury species. ${ }^{\mathbf{4 1}}$ Finally, good resolution $(R>1.5)$, higher recoveries and shorter analyses time (less than $12 \mathrm{~min}$ ) were achieved. As shown in Fig. 5F, signal intensity of $\mathrm{Hg}$ in AFS increased within 1-2\% $\mathrm{HNO}_{3}$ followed by a slightly decrease beyond $5 \%$. In terms of $\mathrm{NaBH}_{4}$, the signal intensity increased with the concentration from 5 to $20 \mathrm{~g} \mathrm{~L}^{-1}$ and differed within 20-25 $\mathrm{g} \mathrm{L}^{-1}$. This probably because the mercury species could not be reduced to $\mathrm{Hg}^{0}$ completely at lower $\mathrm{HNO}_{3}$ and $\mathrm{NaBH}_{4}$ concentrations, but at higher concentrations the mercury vapour would be diluted by the generated hydrogen gas, which could also quench mercury fluorescence. No obvious influence of oxidant concentration on the signal intensity was observed with the help of online decomposed ultraviolet light irradiation system, which could simplify the process and reduce contamination from additional chemicals. Therefore, $20 \mathrm{~g} \mathrm{~L}^{-1} \mathrm{NaBH}_{4}, 2 \% \mathrm{HNO}_{3}$ and $5 \mathrm{~g} \mathrm{~L}^{-1} \mathrm{~K}_{2} \mathrm{~S}_{2} \mathrm{O}_{8}$ were selected in this study.

The effectiveness and commonality of this established method were further evaluated by comparing LODs with other materials (Table 2), testing linearity, sensitivity, accuracy and reproducibility (Table 3 ). Then, mercury species in water and fish tissue samples were detected through the whole process and their concentrations were below the maximum level in drinking water (WHO and China: $<1 \mu \mathrm{g} \mathrm{L}^{-1}$; EPA: $<2 \mu \mathrm{g} \mathrm{L}^{-1}$ ), surface water (EU legislation: $<0.07 \mu \mathrm{g} \mathrm{L}^{-1}$ ) and fish (China: total $\mathrm{Hg}<0.3 \mu \mathrm{g} \mathrm{g}{ }^{-1}$ wet $\left.\mathrm{wt}\right)$. Based on the recoveries of standard addition (Table 4), the prepared nano- $\mathrm{MoS}_{2}$ may provide a new strategy to detect mercury pollutants in environmental and biological samples by HPLC-UV-HG-AFS.

\section{Conclusions}

In this study, a new solid phase extraction method based on nano- $\mathrm{MoS}_{2}$ was established for the enrichment of mercury species in environmental and biological samples. The prepared nano- $\mathrm{MoS}_{2}$ with widened interlayer spacing structure and more exposed sulfur atoms can be served as an excellent adsorbent, which has extraordinary selectivity and high adsorption capacity towards mercury species. The nano-MoS 2 coupled with HPLC-UV-HG-AFS offers a better strategy to enhance sensitivity and simplicity for the simultaneous speciation analysis of trace mercury species in real samples, and it has potential significant importance for environmental monitoring and health assessment.

\section{Conflicts of interest}

There are no conflicts to declare. 


\section{Acknowledgements}

This work was supported by the Natural Science Foundations of China (81673228 and 81473020), and a project funded by the Priority Academic Program Development of Jiangsu Higher Education Institutions (2014).

\section{Notes and references}

1 P. A. Ariya, M. Amyot, A. Dastoor, D. Deeds, A. Feinberg, G. Kos, A. Poulain, A. Ryjkov, K. Semeniuk, M. Subir and K. Toyota, Chem. Rev., 2015, 115, 3760-3802.

2 B. Michalke, D. Willkommen, E. Drobyshev and N. Solovyev, TrAC, Trends Anal. Chem., 2017, DOI: 10.1016/ j.trac.2017.08.008.

3 M. Enrico, G. Le Roux, L. E. Heimburger, P. Van Beek, M. Souhaut, J. Chmeleff and J. E. Sonke, Environ. Sci. Technol., 2017, 51, 5899-5906.

4 J. Mo, Q. Li, X. Guo, G. Zhang and Z. Wang, Anal. Chem., 2017, 89, 10353-10360.

5 Q. Chen, Y. Lin, Y. Tian, L. Wu, L. Yang, X. Hou and C. Zheng, Anal. Chem., 2017, 89, 2093-2100.

6 M. He, L. Huang, B. Zhao, B. Chen and B. Hu, Anal. Chim. Acta, 2017, 973, 1-24.

7 Y. M. Liu, F. P. Zhang, B. Y. Jiao, J. Y. Rao and G. Leng, J. Chromatogr. A, 2017, 1493, 1-9.

8 R. A. Gil, P. H. Pacheco, S. Cerutti and L. D. Martinez, Anal. Chim. Acta, 2015, 875, 7-21.

9 C. Bendicho, C. Bendicho-Lavilla and I. Lavilla, TrAC, Trends Anal. Chem., 2016, 77, 109-121.

10 G. Giakisikli and A. N. Anthemidis, Anal. Chim. Acta, 2013, 789, 1-16.

11 G. Li, M. Liu, Z. Zhang, C. Geng, Z. Wu and X. Zhao, J. Colloid Interface Sci., 2014, 424, 124-131.

12 Y. Hong, D. J. Kim, I. A. Choi, M. Pal, G. Lee, K. M. Nam and W. S. Seo, RSC Adv., 2018, 8, 1089-1097.

13 Y. Huang, J. Tang, L. Gai, Y. Gong, H. Guan, R. He and H. Lyu, Chem. Eng. J., 2017, 319, 229-239.

14 H. Zhao, X. Mu, G. Yang, M. George, P. Cao, B. Fanady, S. Rong, X. Gao and T. Wu, Appl. Energy, 2017, 207, 254-264.

15 X. Guo, X. Zhang, S. Zhao, Q. Huang and J. Xue, Phys. Chem. Chem. Phys., 2016, 18, 228-233.

16 W. Jiang, X. Jin, X. Yu, W. Wu, L. Xu and F. Fu, J. Chromatogr. A, 2017, 1496, 167-173.

17 J. Tang, H. Lv, Y. Gong and Y. Huang, Bioresour. Technol., 2015, 196, 355-363.

18 H. Zhao, H. Fan, G. Yang, L. Lu, C. Zheng, X. Gao and T. Wu, Energy Fuels, 2018, 32, 5338-5344.

19 J. P. Rooney, Toxicology, 2007, 234, 145-156.

20 J. A. Darr, J. Zhang, N. M. Makwana and X. Weng, Chem. Rev., 2017, 117, 11125-11238.
21 K. Ai, C. Ruan, M. Shen and L. Lu, Adv. Funct. Mater., 2016, 26, 5542-5549.

22 H. Li, Y. Li, A. Aljarb, Y. Shi and L. J. Li, Chem. Rev., 2017, DOI: 10.1021/acs.chemrev.7b00212.

23 S. Boandoh, S. H. Choi, J. H. Park, S. Y. Park, S. Bang, M. S. Jeong, J. S. Lee, H. J. Kim, W. Yang, J. Y. Choi, S. M. Kim and K. K. Kim, Small, 2017, 13(39), 1701306.

24 S. Najmaei, Z. Liu, W. Zhou, X. Zou, G. Shi, S. Lei, B. I. Yakobson, J. C. Idrobo, P. M. Ajayan and J. Lou, Nat. Mater., 2013, 12, 754-759.

25 Y. Yu, G. Li, L. Huang, A. Barrette, Y. Q. Cai, Y. Yu, K. Gundogdu, Y. W. Zhang and L. Cao, ACS Nano, 2017, 11, 9390-9396.

26 V. Nicolosi, M. Chhowalla, M. G. Kanatzidis, M. S. Strano and J. N. Coleman, Science, 2013, 340, 1-18.

27 Z. Liu, Y. Wang, Z. Wang, Y. Yao, J. Dai, S. Das and L. Hu, Chem. Commun., 2016, 52, 5757-5760.

28 X. Hai, K. Chang, H. Pang, M. Li, P. Li, H. Liu, L. Shi and J. Ye, J. Am. Chem. Soc., 2016, 138, 14962-14969.

29 F. Jia, Q. Wang, J. Wu, Y. Li and S. Song, ACS Sustainable Chem. Eng., 2017, 5, 7410-7419.

30 V. P. Pham and G. Y. Yeom, Adv. Mater., 2016, 28, 9024-9036. 31 X. Zhang, F. Jia, B. Yang and S. Song, J. Phys. Chem. C, 2017, 121, 9938-9943.

32 C. Lee, H. Yan, L. E. Brus, T. F. Heinz, J. Hone and S. Ryu, ACS Nano, 2010, 4, 2695-2700.

33 S. Z. Butler, S. M. Hollen, L. Cao, Y. Cui, J. A. Gupta, H. R. Gutierrez, T. F. Heinz, S. S. Hong, J. Huang, A. F. Ismach, E. Johnston-Halperin, M. Kuno, V. V. Plashnitsa, R. D. Robinson, R. S. Ruoff, S. Salahuddin, J. Shan, L. Shi, M. G. Spencer, M. Terrones, W. Windl and J. E. Goldberger, ACS Nano, 2013, 7, 28982926.

34 J. Martincova, M. Otyepka and P. Lazar, Chem.-Eur. J., 2017, 23, 13233-13239.

35 H. C. H. Hahne and W. Kroontje, J. Environ. Qual., 1973, 2, 444-450.

36 H. Zhao, X. Mu, G. Yang, C. Zheng, C. Sun, X. Gao and T. Wu, Appl. Surf. Sci., 2017, 420, 439-445.

37 S.-I. Lo, P.-C. Chen, C.-C. Huang and H.-T. Chang, Environ. Sci. Technol., 2012, 46, 2724-2730.

38 C. Peng, M. He, B. Chen, L. Huang and B. Hu, Analyst, 2017, 142, 4570-4579.

39 C. Zhou, H. Zhu, Q. Wang, J. Wang, J. Cheng, Y. Guo, X. Zhou and R. Bai, RSC Adv., 2017, 7, 18466-18479.

40 C. Huang and B. Hu, Spectrochim. Acta, Part B, 2008, 63, 437444.

41 Z. Yun, B. He, Z. Wang, T. Wang and G. Jiang, Talanta, 2013, 106, 60-65. 